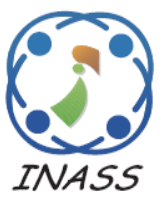

\title{
Analysis, Design, and Manufacture of a Compact UHF RFID Tag Antenna for Operating in a Metallic or Non-Metallic Environments
}

\author{
Younes El Hachimi ${ }^{1 *}$ \\ Abdelmajid Farchi ${ }^{1}$ \\ ${ }^{1}$ Laboratory of Mechanical Engineering, Industrial Management and Innovation, \\ Faculty of Sciences and Technologies, University of Hassan 1st, Settat, Morocco \\ * Corresponding author's Email: yassine.gmih@gmail.com
}

\begin{abstract}
A miniaturized tag antenna is presented in this paper, for operating in the RFID UHF American band, in free space or in a metallic environment. The proposed antenna is printed on a single layer FR4 substrate, and designed first to work in a free space. The shape of the $\pi$-match allowed us to achieve a good matching between the antenna impedance and that of the chip. The correspondence between simulation results in CST and HFSS pushed us to manufacture a prototype of our tag. After that, we simulated the proposed antenna in a metallic area, by adding a square metal plate separated with the antenna by a foam-layer, in order to test the performance of the tag in this environment. An optimization procedure enabled us to achieve a good performance when operating in metallic surroundings. Finally, we tested the reading range of the manufactured tag. We obtained a good range of about $6.5 \mathrm{~m}$. The final design of our proposed tag has a simple structure, a dimension of $51 \times 26,63 \times 0.8 \mathrm{~mm}^{3}$ and which is reduced by $88,64 \%$ compared to the calculated theoretical dimensions of a patch antenna operating at the resonant frequency of $915 \mathrm{MH}$.
\end{abstract}

Keywords: UHF, RFID, Tag, Antenna, Miniaturized, Metallic environment, Free space, Read range.

\section{Introduction}

Radio-frequency identification (RFID) is considered as the most significant identification technology, because it is exploited in a wide range of fields such as positioning and identification of objects [1] or health monitoring with wearables [2], the Internet of Things [3] and communication with different sensors military, passport, supply chain, and so on [4]. This makes it inescapable in the daily life of the person.

The RFID system with allocated low frequency $(125-134 \mathrm{kHz})$, high frequency $(13.56 \mathrm{MHz})$, ultrahigh frequency (UHF) (860-960 MHz), and microwave frequency $(2.45,5.8$, and $24 \mathrm{GHz})$ [5] has pulled attention for its variety of applications as of late. UHF-band RFID systems particularly provide long-range, faster reading and greater information storage capacity [6] than those operated in the lowand high- frequency (LF or HF) bands. For RFID UHF band, each country has its specific frequency band, i.e. 866-869 MHz for Europe, 902-928 MHz for
North and South America and 952- $955 \mathrm{MHz}$ for Japan [7]. Therefore, RFID tags are generally designed to work in a specific region.

The fundamental RFID system is made out of tag [8] from which we can remotely retrieve data, reader [9], and database where we stock identified object information. The physical connection between the reader and the tag is wireless and dependent on the electromagnetic coupling between their antennas. Exchange data between the tag and the reader is accomplished by near-field coupling with a load modulation in LF and HF bands, though, in UHF bands, the principle of backscatter modulation is utilized. In this method, the tag communicates with the interrogator by modulating the received signal and transmitting it back to the reader. The electric field of the propagating signal produces a potential difference crosswise the terminals of the tag antenna. This voltage is converted into DC voltage which powers up the chip. The latter acts as a switch to match or mismatch its internal load to the antenna by 
varying its input impedance leading to the effective modulation of the backscattered signal [10].

RFID tags can be divided into two classes: one is a passive tag, and the other is an active tag. Passive tags do not require an internal power source. They are energized by the reader's signal. In a passive RFID tag, the input impedance of the antenna is matched with the conjugate impedance of the tag IC for maximum power transfer from the antenna to chip [11]. Passive RFID microchips have capacitive impedances. In this manner, the antenna is designed with a larger inductive input impedance.

The accomplishment of tag antenna in design plays a crucial role in the RFID system particularly when it comes to passive operating mode. Because the size of the RFID tag depends only on the size of the antenna, size reduction of the tag antenna is an important concern in the design of compact RFID tags. The tag antenna must to be also designed with better communication qualities for longer detection range and high accuracy. Thus, impedance matching and miniaturization at the same time are the challenges in passive RFID tag antenna design.

Numerous techniques are proposed for the impedance matching such as T-match network [12], double T-matching structure [13] and inductively coupled loop [14]. Other techniques are used to reduce the antenna's dimensions including meandering [15], which increase the electrical length of the tag antenna, fractal, inverted-F antenna (PIFA), Split Ring Resonators (SRR) structures, and slot's technique which consists of cutting slots of different shapes from a patch antenna [16-18].

In some applications, the tags require to be mounted on items of different kinds of materials, such as glass, wood, and even metallic objects like steel plates or steel containers. However, the interaction between the tag and the materiel makes the design of tag antenna challenging especially when the tag is mounted on conductive materials [19] or when it is placed in a metallic environment, due to totally different radiation boundaries. It can display a significant performance degradation due to a shift in operating frequency, distorted radiation patterns and impedance mismatch, which quickly reduce its read range or even cannot be read. To mitigate this problem, several antennas have been proposed in the literature. The most commonly used method is to incorporate a conductive ground plane beneath the antenna [20-22]. Printed inverted-F antenna (PIFA) is one of the commonly used structure for metal objects tagging. However, the fabrication cost for this antenna is high due to the existence of a shorting plate or shorting pin in the antenna design and they have also the drawback of a large size [23-25].
The motivation of this research is to design a novel RFID UHF size-reduced tag antenna working in a free space, with a simple configuration. The advantage of our design resides in the fact that it can also function in a metallic environment with a simple modification that consists in enlarging the substrate extremities. This shows that our antenna can operate in this area, with a simple configuration (planar) that does not contain a shorting plate or shorting pin in the antenna design, which reduces the manufacturing cost of our tag.

The antenna operates at the $902-928 \mathrm{MHz}$ bands allocated for RFID applications in North and South America. The article is organized as follows: Section 2 describes the configuration of the proposed antenna. Section 3 is divided into two parts and presents the obtained results and a discussion for the proposed tag working in free space and in a metallic area. A table is also generated for comparing the proposed tag antenna with some other structures available in the literature, while a conclusion is made in Section 4 to summarize the paper.

\section{Antenna design and Input impedance of the RFID chip}

A miniaturized planar microstrip patch antenna for the UHF RFID tag is proposed and illustrated in Fig. 1. It has a very simple design and made out of a modified T-match linked at both ends with meanderline. To achieve conjugate matching between the tag chip (Alien Higgs-4) and the proposed antenna, the $\pi$ - shape is applied. The folded dipole, which modifies the electrical length, is directly coupled to the $\pi$-structure resulting reduction of the physical size of the antenna and consists of a dipole, having a width of $0,75 \mathrm{~mm}$, bent into a serpentine shape structure. The radiating element of the tag is printed on a thin, single-layer and inexpensive FR4 substrate (permittivity $\varepsilon r=4.4$ and loss tangent $\tan \delta=0.0025$ ) with a thickness of $\mathrm{h}=0.8 \mathrm{~mm}$ and a total area of $46 \times 2,63 \times 0,8 \mathrm{~mm}^{3}$. The antenna design is simulated using CST (Computer Simulation Technology) microwave studio [26], whose numerical analysis is based on the Finite Integration Technique, and the optimized parameters are enlisted in Table 1.

The input impedance of the microchip used in UHF RFID tags is capacitive. Tag antennas are designed to have an inductive impedance to deliver the maximum power transfer. The antenna's input impedance, $\mathrm{Za}$ should be the complex impedance conjugate of the chip, $\mathrm{Zc}\left(\mathrm{Zc}=\mathrm{Za}^{*}\right)$. The Higgs-4 EPC global Class 1 Gen2 UHF RFID microchip fabricated by Alien Technology [27] is used. The chip packaging is SOT-323. It is easy to solder this 
sort of packaging manually. The foremost important advantage of using this chip is the minimum communication power of radio-frequency that can reach the level of $-18.5 \mathrm{dBm}$. The input impedance of the microchip is $\mathrm{Zc}=18,43-\mathrm{j} 181,2 \Omega$ at $915 \mathrm{MHz}$. The impedance of the antenna is therefore intended for $\mathrm{Za}=18,43+\mathrm{j} 181,2 \Omega$.

A parallel or series equivalent circuit $\mathrm{Rp}, \mathrm{Cp}, \mathrm{Rs}$, Cs can model the RFID impedance. It is possible to calculate these parameters as shown in Eqs. (1) - (4) [28]. We have modeled this microchip in this work with a series equivalent circuit $(\mathrm{Rs}=18,43 \Omega$; $\mathrm{Cs}=$ $0.955 \mathrm{pF}$ ).

The equation parameters are as follows:

$$
\begin{aligned}
& R_{p}=\frac{\operatorname{Im}_{\text {chip }}{ }^{2}+R_{\text {chip }}{ }^{2}}{R_{\text {chip }}} \\
& C_{p}=\frac{\operatorname{Im}_{\text {chip }}}{2 \pi f .\left(\operatorname{Im}_{\text {chip }}{ }^{2}+R_{\text {chip }}{ }^{2}\right)} \\
& R_{s}=R_{\text {chip }} \\
& C_{s}=\frac{1}{2 \pi f . I m_{\text {chip }}}
\end{aligned}
$$

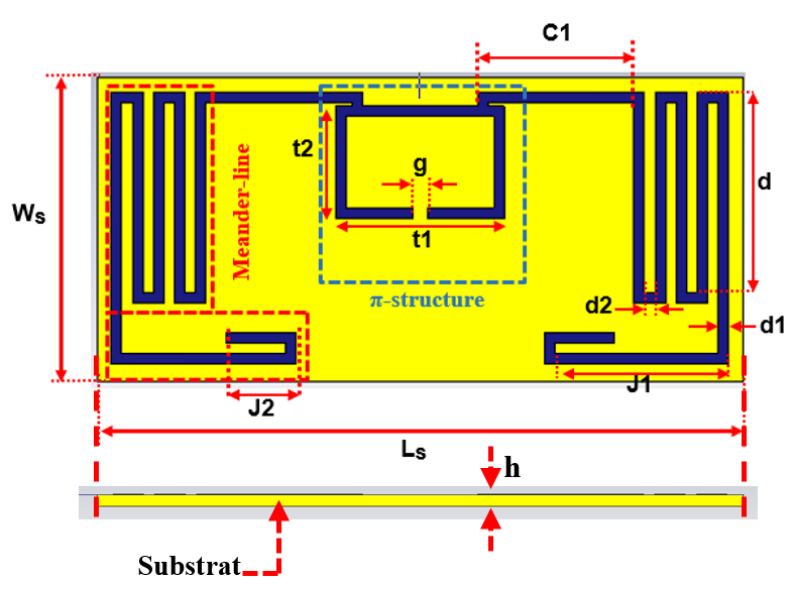

Figure. 1 Geometry of the proposed tag antenna

Table 2. Dimensions of the proposed tag antenna

\begin{tabular}{|c|c|c|c|}
\hline Parameter & $\begin{array}{c}\text { Value } \\
(\mathbf{m m})\end{array}$ & Parameter & $\begin{array}{c}\text { Value } \\
(\mathbf{m m})\end{array}$ \\
\hline $\mathrm{Ls}$ & 46 & $\mathrm{~d}$ & 15 \\
\hline $\mathrm{Ws}$ & 21,63 & $\mathrm{~d} 1$ & 0,75 \\
\hline $\mathrm{h}$ & 0,8 & $\mathrm{~d} 2$ & 0,75 \\
\hline $\mathrm{t} 1$ & 12 & $\mathrm{~J} 1$ & 13,15 \\
\hline $\mathrm{t} 2$ & 8 & $\mathrm{~J} 2$ & 5 \\
\hline $\mathrm{C} 1$ & 11,9 & $\mathrm{G}$ & 1 \\
\hline
\end{tabular}

\section{Results and discussions}

First, a compact tag has been designed to operate in a non-metallic area. Then, simulations were carried out for the case when the tag was located in a metallic environment, in order to test the effect of a metal (copper plate) on the performance of our antenna. We placed a foam layer between the tag and the metal plate. After that, we have carried out a parametric study on the dimensions of the foam, the metal plate, and the substrate of our antenna, to see the impact of each one on the performances of our antenna.

\subsection{Tag antenna for non-metallic surfaces}

The simulated reflection coefficient characteristic of the designed antenna as a function of frequency is depicted in Fig. 2. It reaches a value of $-24,13 \mathrm{~dB}$ at $915,6 \mathrm{MHz}$ with a bandwidth of $12,29 \mathrm{MHz}$ ranging from 909,69 to $921,98 \mathrm{MHz}$ in CST, while, in HFSS, it is equal to $-23,5 \mathrm{~dB}$ at $909 \mathrm{MHz}$ extending from 903,4 to $915,1 \mathrm{MHz}$ which means a bandwidth of $11,7 \mathrm{MHz}$. Because of the calculation method used in each software, we can observe a little distinction in return loss acquired with the two simulators. CST is based on the Finite Integration Technique (FIT) and HFSS is founded on the Finite Element (FEM) method [29]. Therefore, it remains an acceptable agreement between them. These values of S11 reflect that our antenna is well adapted.

Another parameter can demonstrate the antenna's adaptation: the input impedance. Fig. 3 illustrates the simulated real and imaginary part of the suggested tag antenna's input impedance. It is equivalent to $\mathrm{Za}=(21$, $12+179,8 \mathrm{j})$ and $\mathrm{Za}=(24,42+193,74 \mathrm{j})$ respectively at $915,6 \mathrm{MHz}$ in CST and HFSS. These results are nearly equivalent to the value of the complex conjugate of the chip impedance $\mathrm{Zc}=(18,43-\mathrm{j} 181,2)$. This ends up in the observation that the $\pi$-shape has enabled us to accomplish a good conjugate matching between the antenna and the chip reducing the losses owing to reflections.

Fig. 4 shows the 2D simulated radiation pattern of the proposed tag antenna in E-plane and H-plane at $915 \mathrm{MHz}$. It is bidirectional in the E-plane and almost omnidirectional in the H-plane. We can notice that the gain reached a value of $0,83 \mathrm{~dB}$ and $1,2 \mathrm{~dB}$ respectively in CST and HFSS at $915 \mathrm{MHz}$.

Once the structure is validated using two simulators (HFSS and CST), the dimensions are fixed and the performance of the RFID tag is known, the tag is manufactured as shown in Fig.5. The RFID chip is soldered directly on the antenna through the two connection pads of the chip. 


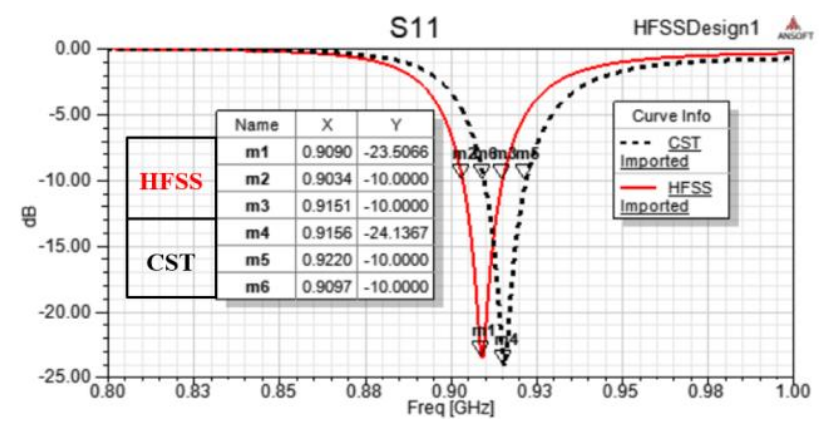

Figure. 2 Simulated return loss of the proposed tag antenna in CST and HFSS
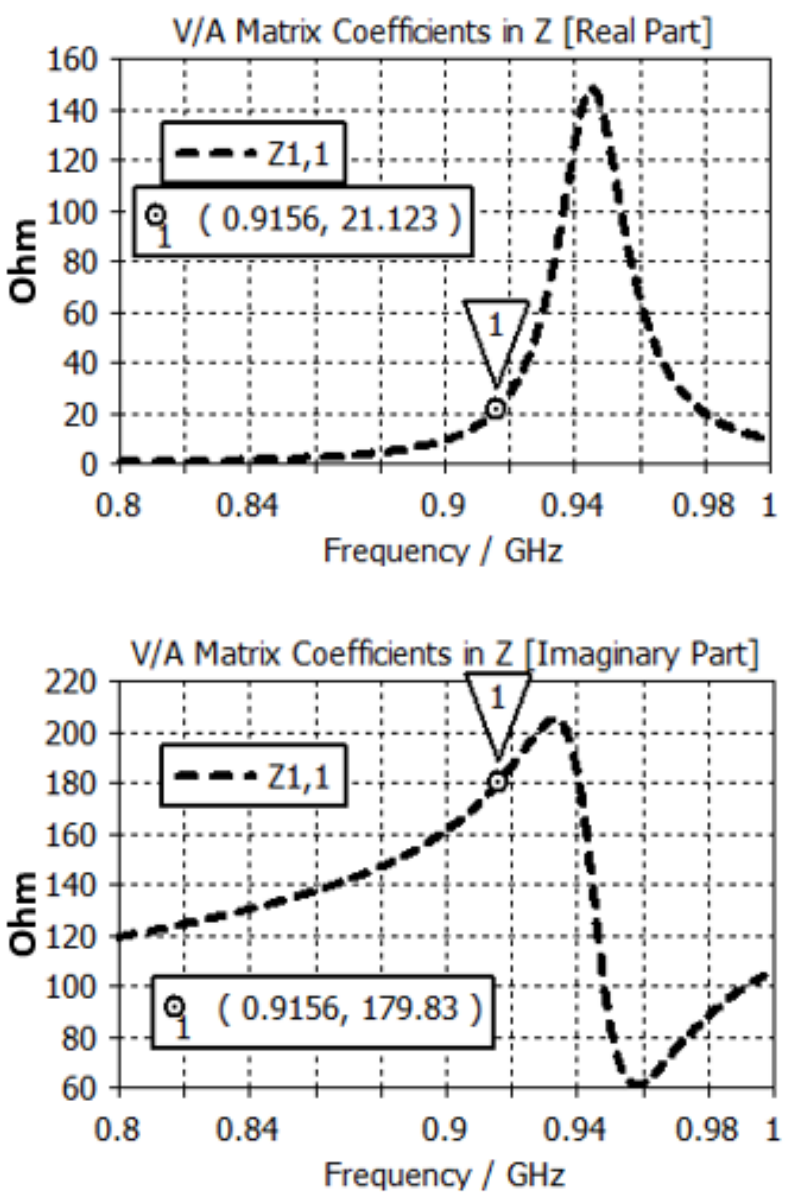

(a)

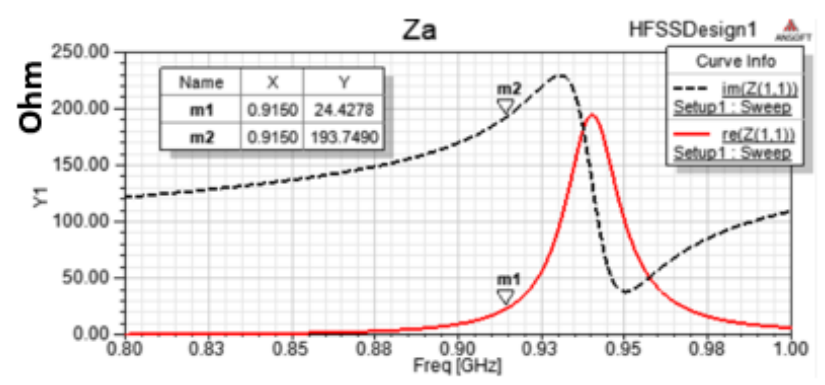

(b)

Figure. 3 Simulated input impedance of the proposed: (a) in CST and (b) HFSS

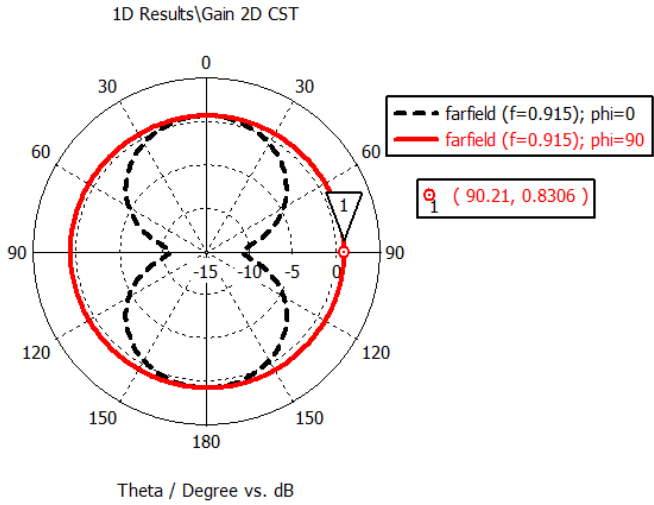

(a)

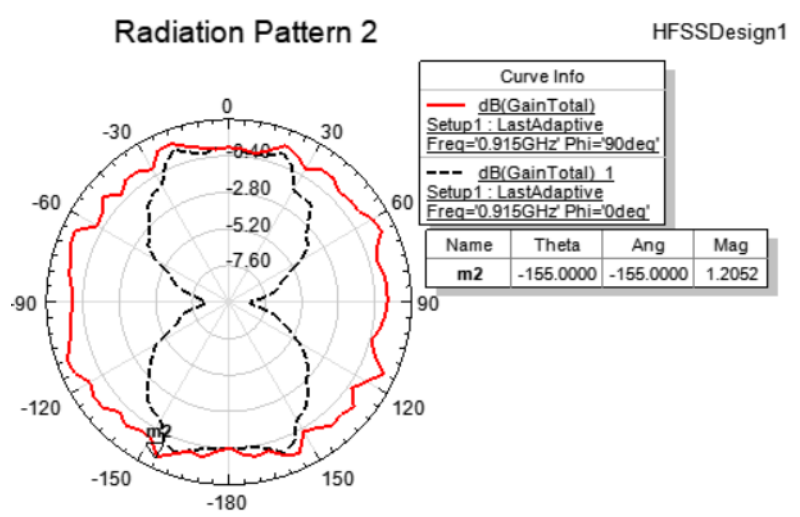

(b)

Figure. 4 Simulated radiation pattern of the proposed tag antenna in E-plane and H-plane at $915 \mathrm{MHz}$ : (a) in CST and (b) HFSS.

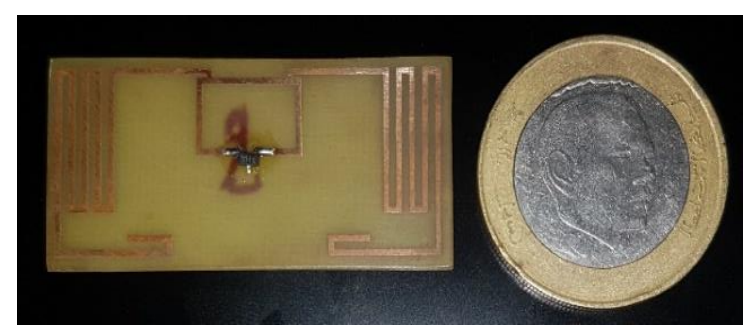

(a)

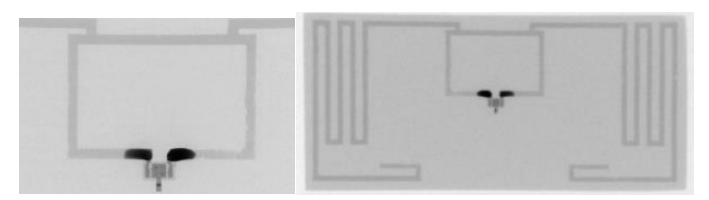

(b)

Figure. 5 (a) Photograph of fabricated Tag antenna, and (b) Location of ALIEN H4 chip using X-Ray

\subsection{Tag antenna for metallic environment}

This time, we simulated our antenna with a metal plate to see its effect on our tag. A foam layer (polyethylene foam with $\varepsilon \mathrm{r}=1.03$, and $\tan \varphi=$ 0.0001) [30] has been introduced between them, as shown in Fig. 6.

As we have already mentioned, when the RFID 


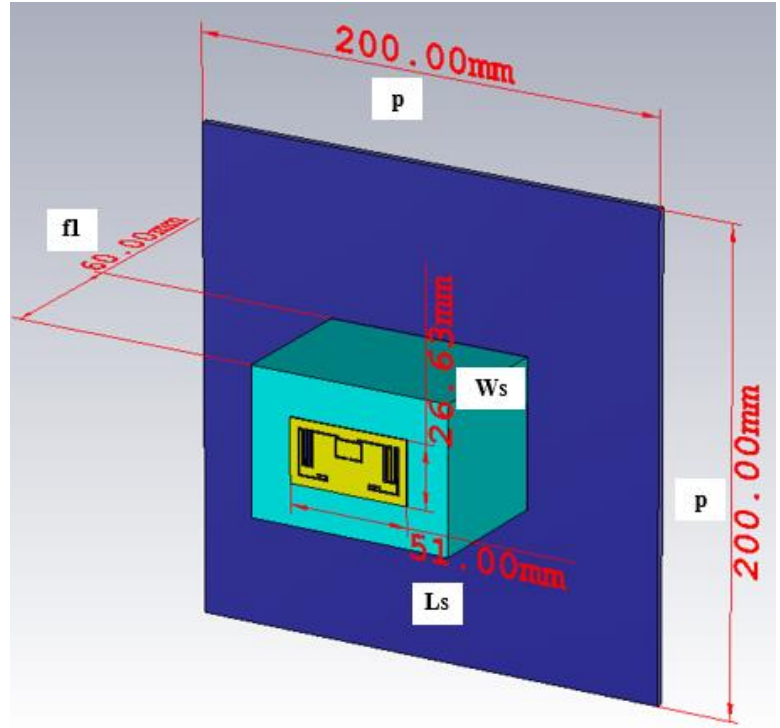

Figure. 6 Proposed tag for operating in a metallic environment

tag antenna is placed in a metallic enclosure or mounted on metal objects, this latter has a negative impact on the tag antenna's performance in terms of the resonant frequency and antenna impedance.

Therefore, to justify the choice of the prototype's final dimensions, a parametric study was conducted with CST on the effects of the metal plate to provide a better understanding of the antenna operation. The values in Table 1 are used for all simulations as reference dimensions. Simulations were performed on "fl", the thickness of the polyethylene foam, "p", the dimensions of the steel plate, and " $\mathrm{f}$ ", the stretching of the substrate on the reflection coefficient of the proposed antenna.

The first step in our design is to choose the appropriate distance $\mathrm{f} 1$ to start with. The effects of variation the distance between the tag and the metal plate (f1) are depicted in Fig. 7. It can be clearly observed, from the figure, that the simulated impedance matching improves with increasing $\mathrm{f} 1$ from 40 to $80 \mathrm{~mm}$. A value of $60 \mathrm{~mm}$ has been chosen as the appropriate value.

The impact of changing steel plate dimensions (p) is now examined and the results are shown in Fig. 8. The copper plate's size varies between $100 \mathrm{~mm}$ and $400 \mathrm{~mm}$. It is seen from the graph that the resonance frequency shift to a higher frequency as $\mathrm{p}$ increases and the adaptation decreases. The best result was observed when the value of $\mathrm{p}$ was $200 \mathrm{~mm}$.

Finally, we have optimized the substrate dimensions of the proposed antenna so that our tag can operate at the American band (902-928 MHz), the Chinese operating band (920-924.5 MHz) and the Korean and Japanese band (917-923.5 MHz), without

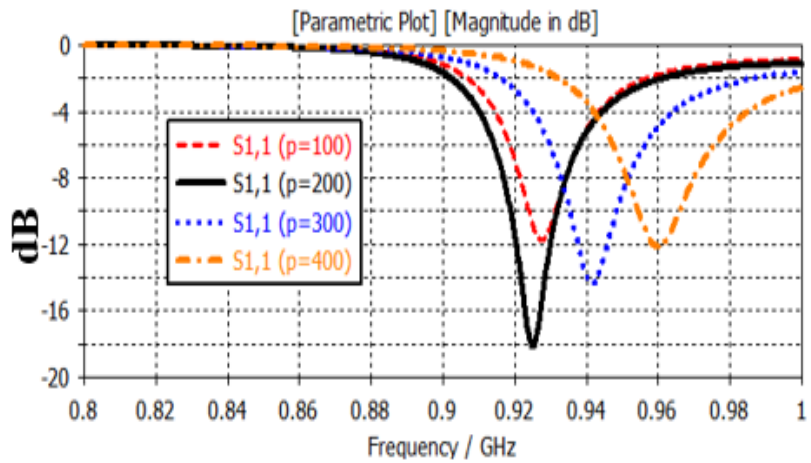

Figure. 7 The effect of the variation of "p" on the return loss

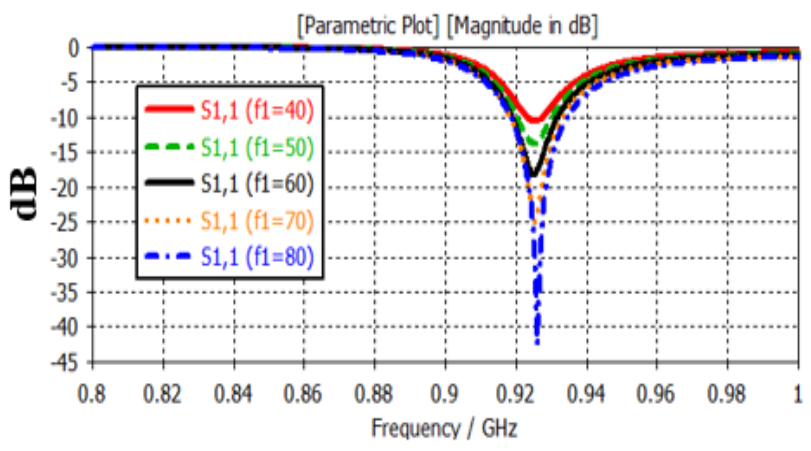

Figure. 8 The effect of various "fl" on the return loss

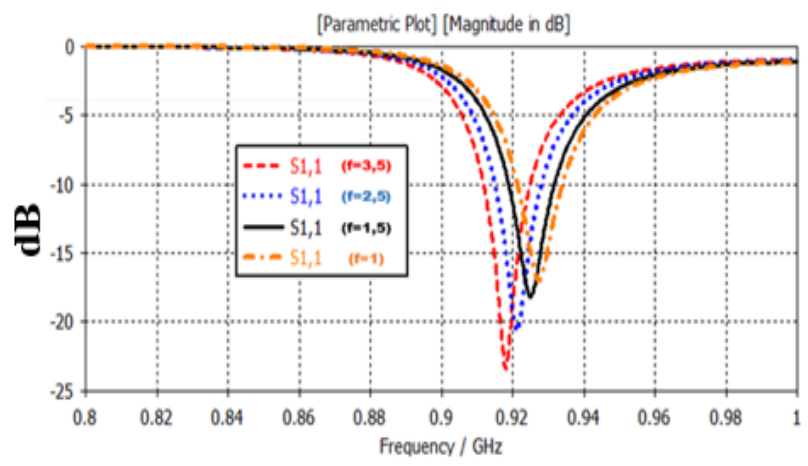

Figure. 9 The simulated reflection coefficient as a function of different values of "f"

modifying the original design. Fig. 9 plotted the reflection coefficient of our RFID tag with different values of " $\mathrm{f}$ " when "f1" and "p" are fixed at $60 \mathrm{~mm}$ and $200 \mathrm{~mm}$ respectively. It is observed that the resonance frequency shifts slightly towards lower frequencies and that the reflection coefficient increases with the rise of "f", which means that the adaptation improves with the enlargement of the substrate. The best result was observed when the fvalue was $2.5 \mathrm{~mm}$.

\subsection{Simulations results of the proposed tag without metal and close to a metal plate}

Fig. 10 shows the simulated reflection coefficient of the proposed tag antenna with and without metal. 


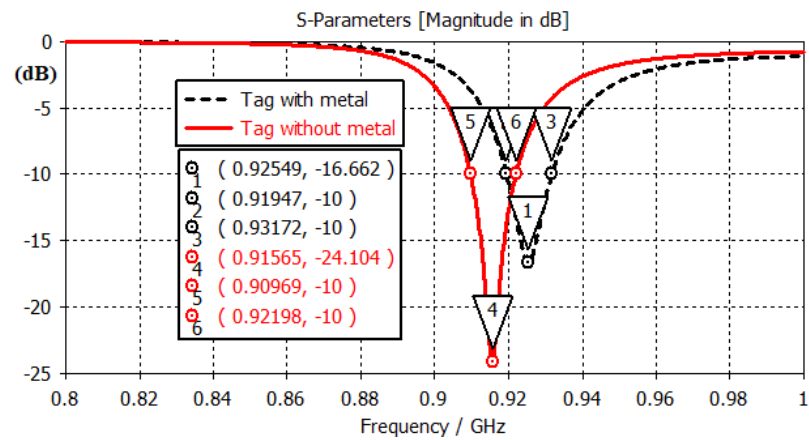

Figure. 10 Simulated reflection coefficient of the proposed tag with and without metal

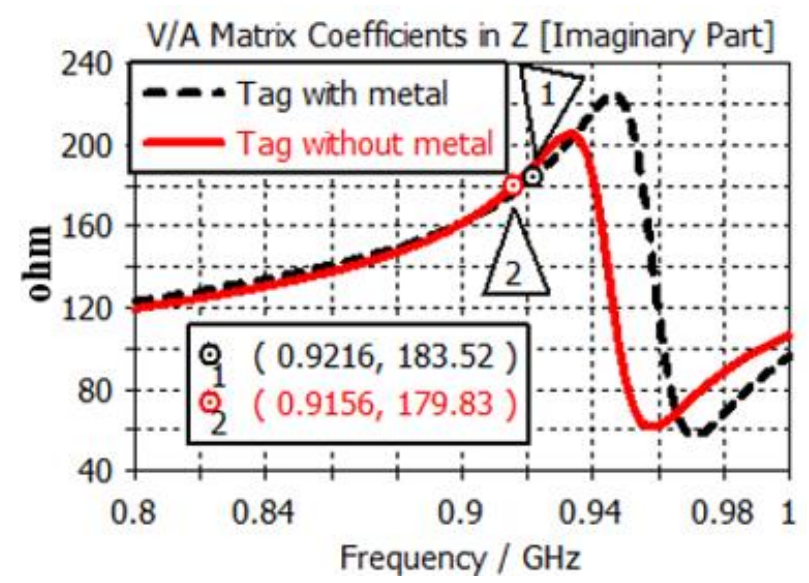

(a)

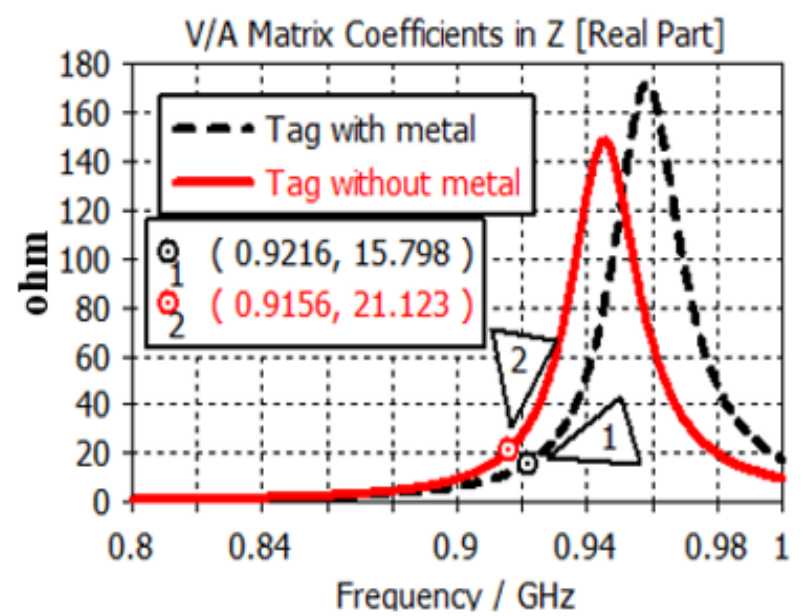

(b)

Figure. 11 Simulated Input impedance of the proposed tag with and without metal: (a) real part and (b) imaginary part

We notice that the simulated return loss, of our tag without a metal plate, reaches a value of $-24,13 \mathrm{~dB}$ at $915,6 \mathrm{MHz}$ with a bandwidth of $12,59 \mathrm{MHz}$ ranging from 909,69 to $921,98 \mathrm{MHz}$. While, for the tag with metal (in a metallic area), we obtained a bandwidth of $12,25 \mathrm{MHz}(915,5-928,09 \mathrm{MHz})$ with a value of $\mathrm{S} 11$ of $-18,7 \mathrm{~dB}$ at the resonant frequency of 921,6

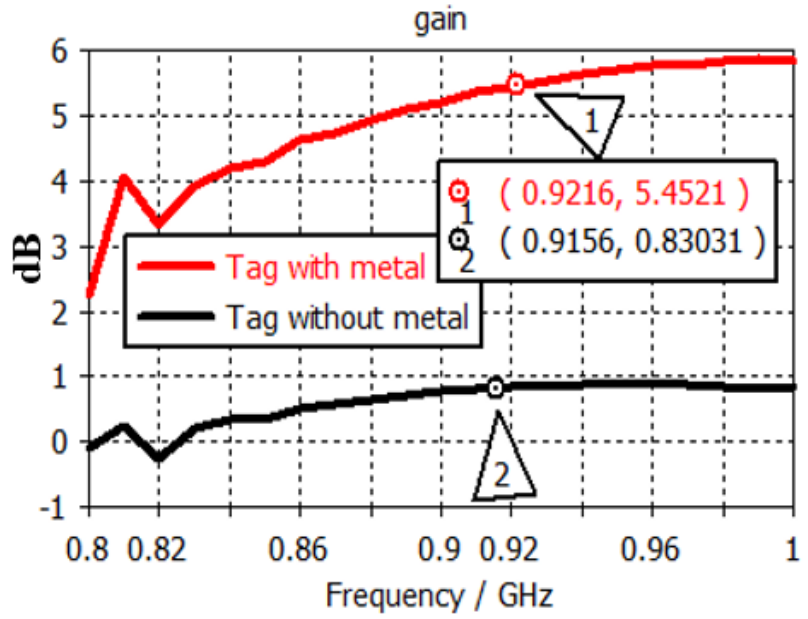

Figure. 12 Simulated gain, as a function of frequency, of the proposed tag with and without metal

MHz. The simulated resonance frequency of the metal tag antenna has been shifted by about $6 \mathrm{MHz}$ to higher frequencies compared to the metal-free tag (in the open air).

The following figure (Fig.11) shows the simulated real and imaginary part of tag impedance as a function of the frequency. It is equal to $\mathrm{Za}=179,83+\mathrm{j} 21,12 \Omega$ and $\mathrm{Za}=183,52+\mathrm{j} 15,79 \Omega$ for the tag in free space and for the tag mounted on a metal plate respectively and therefore having excellent impedance match with the chip impedance which is $\mathrm{Zc}=18,43+\mathrm{j} 181,2 \Omega$. Good impedance matching could ensure a longer antenna reading distance, which is an important condition for RFID applications.

Fig. 12 shows the simulated gains of our tag with and without metal. When the proposed tag was placed in free space, a peak gain of about $0,83 \mathrm{~dB}$ at 915,6 $\mathrm{MHz}$ was obtained. However, the peak gain reaches $5,45 \mathrm{~dB}$ at $921,6 \mathrm{MHz}$ when the tag was placed closer to the metal. This is due to the fact that the metal plate is a conductive element.

A satisfactory simulation results were obtained for the tag when it is placed near the metal. Therefore, our antenna can operate in a metallic environment. The difference between the tag structure in free space and in metallic surroundings is the spreading of the substrate ( $2.5 \mathrm{~mm}$ on each side) for the tag when it is located in the proximity of the metal.

\subsection{Theoretical and measured read range}

Among the vital properties for the design of the RFID tag is the reading range. It brings us information about the maximum distance at which the tag receives the minimum threshold power needed to turn on and scatter a signal back, and therefore the maximum distance at which the reader 
can detect the tag antenna. The theoretical reading range can be obtained using Friis-free space equation formula (Eq. (5)) [31]:

$$
r=\frac{\lambda}{4 \pi} \sqrt{\frac{E I R P \cdot G_{t} \cdot \tau}{P_{\text {chip }}}}
$$

$\lambda$ is the wavelength and EIRP is the effective isotropically radiated power ( $4 \mathrm{~W}$ in the USA) determined by local country regulations. Pchip is the minimum threshold power necessary to activate the chip, Gt is the gain of the receiving tag antenna, and $\tau$ is the power transmission coefficient. Hence, the calculated maximum read range was found to be $14.48 \mathrm{~m}$ at $915 \mathrm{MHz}$.

The reading range of the tag antenna was measured in the situation in Fig.13 at MASCIR Center. The measuring system is made up of a host, a reader controller $(\mathrm{F} 5860-\mathrm{H})$, a circularly polarized reader antenna (A4108), and the fabricated tag as shown in the Fig.13. The reference reader antenna has a frequency range of 840 to $960 \mathrm{MHz}$ and a gain of $8 \mathrm{dBi}$. The input power of the reader antenna is $1 \mathrm{~W}$ $(30 \mathrm{dBm})$. The whole system is controlled by software developed at MASCIR Center.

We can see, from Fig.13, that the maximum measured reading range is $6.5 \mathrm{~m}$. We notice that it is lower than the theoretical value $(14.48 \mathrm{~m})$ calculated using the Friis equation. This difference is due to the presence of the metal in the tag's environment as proved in the figure.

In order to valorize our proposed tag, we compared our design with various tags recently published in the literature, operating in a metallic milieu. This comparison, illustrated in Table 2, is made in terms of the overall dimensions of the antenna, the reading range, the use or not of the shortcircuit elements and finally the dimensions of the metal plate. Referring to Table 2 , we can clearly see that the volume of the proposed tag is less voluminous than the other antennas, which means that it has the compact size. In addition to its compactness, it has a simple structure that does not contain any short-circuit elements (vias and pins), which makes it easy to manufacture with a reduced cost. In terms of reading distance, our tag has a longer reading range than the tags published in [23,24], and almost similar to that of [25]. We can conclude that our tag offers an optimal reading range compared to its miniature size. In addition to its good radiation and adaptation performance, as well as its simple structure, our antenna can be a good candidate for tags operating in metal or non-metal environments in the UHF band.
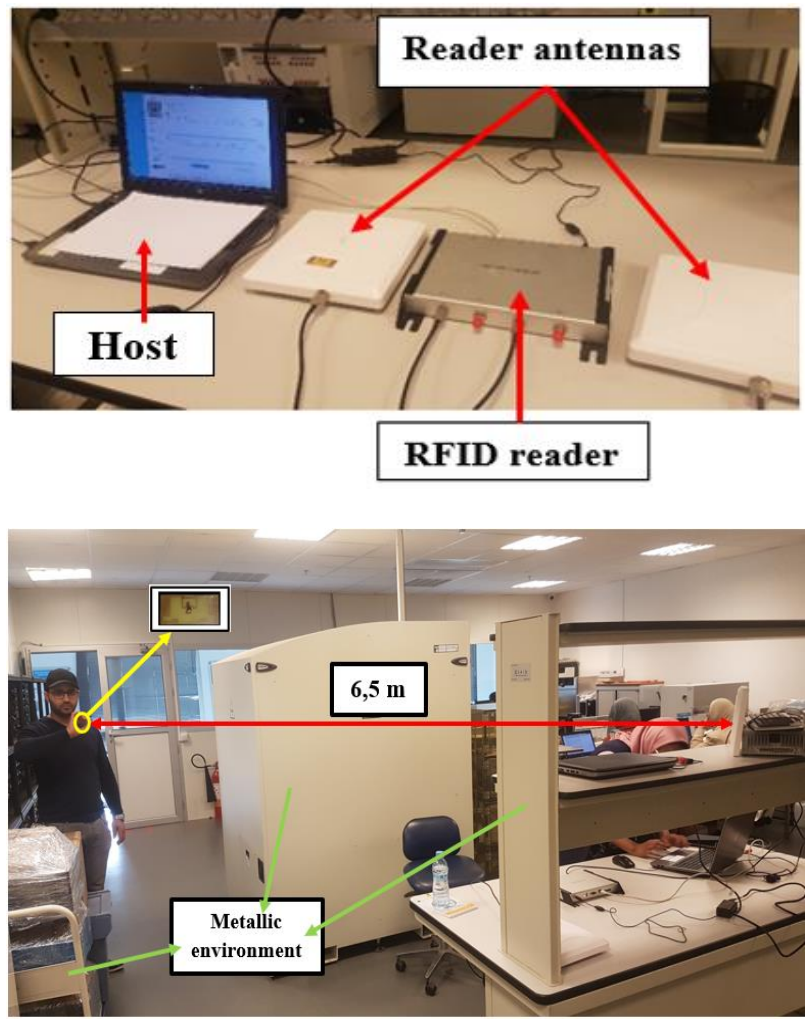

Figure. 13 Measured read range of the proposed RFID tag antenna

Table 2. Comparison of the proposed tag in a metallic environment with other designs

\begin{tabular}{|c|c|c|c|c|}
\hline & {$[23]$} & {$[24]$} & {$[25]$} & $\begin{array}{c}\text { This } \\
\text { work }\end{array}$ \\
\hline $\begin{array}{c}\text { Size } \\
\left(\mathrm{mm}^{3}\right)\end{array}$ & $\begin{array}{c}60 \times 60 \times \\
1,6\end{array}$ & $\begin{array}{c}35 \times 100 \\
\times 3\end{array}$ & $\begin{array}{c}45 \times 45 \times \\
1,27\end{array}$ & $\begin{array}{c}\mathbf{5 1 \times 2 6} \\
\mathbf{6 3} \times \mathbf{0 , 8}\end{array}$ \\
\hline $\begin{array}{c}\text { Read } \\
\text { range }\end{array}$ & 4,8 & 5,5 & 6,8 & $\mathbf{6 , 5}$ \\
\hline $\begin{array}{c}\text { Shorting } \\
\text { elements }\end{array}$ & Pins & Vias & Vias & No \\
\hline $\begin{array}{c}\text { Metal } \\
\text { plate size } \\
(\mathrm{cm})\end{array}$ & $15 \times 15$ & $21 \times 13$ & $30 \times 30$ & $\mathbf{2 0 \times 2 0}$ \\
\hline
\end{tabular}

\section{Conclusion}

A novel compact tag antenna for passive UHF RFID applications is presented. It is set on the economical FR4 substrate and has a dimension of 46 x $21,63 \times 0,8 \mathrm{~mm}^{3}$.in the case of operating in a free space. It can even work in metallic environment with the enlargement of the substrate of $2.5 \mathrm{~mm}$ from each side which means a total size of $51 \times 26,63 \times 0.8 \mathrm{~mm}^{3}$. It provides a stable performance when it is placed in a metallic milieu and reached a measured read range 
of $6.5 \mathrm{~m}$. This miniaturized tag is reduced of about $88,64 \%$ compared to the calculated theoretical dimensions of a patch antenna operating at the resonant frequency of $915 \mathrm{MH}$. Due to its small profile, low-cost substrate, and the fact that it does not contain a ground plane, short-circuit pins or probes, the antenna can be easily manufactured, potentially reducing costs. A prototype of the tag antenna was fabricated. Such a tag design is found to be very promising for metallic or non-metallic UHF RFID applications.

\section{Acknowledgments}

The authors would like to thank Ms. Ilham Bouzida, head of the microelectronics department of the Moroccan Foundation for Advanced Research and Innovation (MASCIR), for their kind support in the framework of the measurement experiment.

\section{References}

[1] S. Azzouzi, M. Cremer, U. Dettmar, R. Kronberger, and T. Knie, "New measurement results for the localization of UHF RFID transponders using an angle of arrival (AoA) approach", In: Proc. of IEEE International Conference on RFID, pp. 91-97, Apr. 2011.

[2] S. Amendola, L. Biachi, and G. Marrocco, "Movement detection of human body segments", IEEE Antennas Propagat. Mag., Vol. 57, No. 3, pp. 23-37, 2015.

[3] A. Rghioui and A. Oumnad, "Internet of Things: Surveys for Measuring Human Activities from Everywhere", International Journal of Electrical and Computer Engineering (IJECE), Vol. 7, No. 5, pp. 2474-2482, 2017.

[4] F. Xavier, O. K Hikage, M. S. de P. Pessoa, and A. L. Fleury, "A View about RFID Technology in Brazil", In: Proc. of PICMET 2010 Technology Management for Global Economic Growth, pp. 1-9, 2010.

[5] S. Bhaskar, S. Singhal, and A. K. Singh, "Folded-slot active tag antenna for $5.8 \mathrm{GHz}$ RFID applications", Prog Electromagn. Res. C., Vol. 82, pp. 89-97, 2018.

[6] D. O. Oyeka, J. C. Batchelor, and A. M. Ziai, "Effect of skin dielectric properties on the read range of epidermal ultra, high frequency radiofrequency identification tags", Healthcare Technol. Lett., Vol. 57, No. 2, pp. 78 - 81, 2017.

[7] T. V. Koskinen, H. Rajagopalan, and Y. R. Samii, "A thin multi-slotted dual patch UHFband metal-mountable RFID tag antenna", Microw. Opt. Technol. Lett., Vol. 53, pp. 40-47, 2011.
[8] Y. El hachimi and A. Farchi, "A Novel Compact Antenna for Passive UHF RFID Tag Using $\pi$ Match and Meander Techniques", In: Proc. of Third International Conference on Computing and Wireless Communication Systems, 2019.

[9] Y. El Hachimi, Y. Gmih, M. Makroum, and A. Farchi, "A Compact Dual-band Antenna including Symmetrical Slots for 2.45/5.8 GHz Handheld RFID Reader Applications", In: Proc. of the 4th International Conference on Optimization and Applications (ICOA), 2018.

[10] B. Barman, S. Bhaskar, and A. K. Singh, "Spiral resonator loaded S-shaped folded dipole dual band UHF RFID tag antenna", Microw. Opt. Technol. Lett., pp. 1-7, 2018.

[11] S. Bhaskar, S. Singhal, and A. K. Singh, "Folded-Slot Active Tag Antenna for $5.8 \mathrm{GHz}$ RFID Applications", Progress in Electromagnetics Research C, Vol. 82, pp. 8997, 2018.

[12] Y. Gmih and A. Farchi, "A New Design of a Miniaturized UHF-RFID Passive Tag Antenna Based on L-Shape Radiators with Meandered Dipole", In: Proc. of Third International Conference on Computing and Wireless Communication Systems, 2019.

[13] C.-W. Chiu, M.-C. Tsai, H.-C. Wang, and T.-F. $\mathrm{Wu}$, "Broadband Tmatching loop tag antenna design for on-body UHF RFID applications", Microwave and Optical Technology Letters, Vol. 56, No. 5, pp. 1194-1200, 2014.

[14] Q. Liu, Y. F. Yu, and S. He, "Capacitively loaded, inductively coupled fed loop antenna with an omnidirectional radiation pattern for UHF RFID tags", IEEE Antennas Wireless Propag. Lett., Vol. 12, pp. 1161-1164, 2013.

[15] Y. Gmih, Y. El Hachimi, E. Makroum, and A. Farchi, "Miniature RFID Antenna at UHF Band using Meander-Line Technique", International Journal of Electrical and Computer Engineering (IJECE), Vol. 8, No. 4, pp. 2280-289, 2018.

[16] D. K. Naji, J. S. Aziz, and R. S. Fyath, "Design of Miniaturized Fractal RFID Tag Antenna with Forced Impedance Matching", International Journal of Electromagnetics and Applications, Vol. 2, No. 5, pp. 129-139, 2012.

[17] S. R. Lee, E. H. Lim, F. L. Bong, B. K. Chung, and K. Y. Lee, "Miniature PIFA-like Patch Antenna for UHF RFID Tag Design", In: Proc. of 2018 IEEE Asia-Pacific Conference on Antennas and Propagation (APCAP), 2018.

[18] N. H. Daud, A. Ismail, A. Reda, H. Alhawari, A. Sali, and M. F. A. Rasid, "Integration of Split Ring Resonators (SRRs) to UHF RFID Tag Antenna for Size Reduction", In: Proc. of 
International Conference on Engineering Technology and Technopreneuship (ICE2T), pp. 204-208, 2014.

[19] T. Bjorninen, L. Sydanheimo, L. Ukkonen, and Y. Rahmat-Samii, "Advances in antenna designs for UHF RFID tags mountable on conductive items", IEEE Antennas Propag. Magz., Vol. 56, No.1, pp. 79-103, 2014.

[20] H. Sun, B. Tao, and O. M. Ramahi, "Proximity coupled cavity backed patch antenna for long range UHF RFID tag", IEEE Trans. Antennas Propag., Vol. 64, No. 12, pp. 5446-5449, 2016.

[21] H. Chen and Y. Tsao, "Low-Profile PIFA array antennas for UHF band RFID tags mountable on metallic objects", IEEE trans. Antennas Propag., Vol. 58, No. 4, pp. 1087-1092, 2010.

[22] E. S. Yang and H. W. Son, "Dual-polarised metal-mountable UHF RFID tag antenna for polarisation diversity", Electron. Lett., Vol. 52, No. 7, pp. 496-498, 2016.

[23] C.-H. Chen and S.-T. Huang, "Low-profile CP RFID hard tag antenna with short- circuited microstrip-fed line mounted on metallic plane", Int. J. RF Microw Comput. Aided Eng., 2018.

[24] B. Tao, H. Sun, and O. M. Ramahi, "RFID Tag Antenna for Metallic or Non-Metallic Surfaces", Progress in Electromagnetics Research C, Vol. 59, pp. 51-57, 2015

[25] S. Zuffanelli, G. Zamora, F. Paredes, P. Aguila, F. Martin, and J. Bonache, "On-metal UHFRFID passive tags based on complementary split-ring resonators", IET Microw. Antennas Propag., Vol. 11, No. 7, pp. 1040-1044, May. 2017.

[26] CST Studio Suite version 2015 :http://www.cst.com/Content/Products/DS /Overview.aspx.

[27] Higgs 4 IC Datasheet. An EPCglobal Complaint Class-1 Gen-2 ISO/IEC 18000-6C UHF RFID Integrated Circuit, Alien Technology (2017).

[28] A. Ghiotto, "Design of UHF RFID Tag Antennas, Application to Material Jet Realization", Thesis in Institut Polytechnique de Grenoble, 2008.

[29] http://www.ansys.com/Products/Electronics/A NSYS+HFSS.

[30] C.-W. Moh, E.-H. Lim, F.-L. Bong, and B.-K. Chung, "Miniature coplanar-fed folded patch for metal mountable UHF RFID tag", IEEE Trans. Antennas Propag., Vol. 66, No. 5, pp. 22452253, 2018.

[31] T. Deleruyelle, P. Pannier, M. Egels, and E. Bergeret, "Dual band mono-chip HF-UHF tag antenna", In: Proc. of IEEE Antennas Propag. Soc. Int. Symp., pp. 1-4, 2010. 